\title{
Assessment of medication adherence among Type 2 Diabetic patients in Quetta city, Pakistan
}

Iqbal $\mathrm{Q}^{1}$, Bashir $\mathrm{S}^{2}$, Iqbal $\mathrm{J}^{1}$, Iftikhar $\mathrm{S}^{3},{ }^{*} \operatorname{Godman} \mathrm{B}^{4,5}$.

${ }^{1}$ Faculty of Pharmacy \& Health Sciences, University of Balochistan, Quetta, Pakistan

Emails: dr.qaiseruob@gmail.com; drjaveidiqbal@hotmail.com

${ }^{2}$ Faculty of Pharmacy, University of Sargodha, Punjab, Pakistan. Email: sajidpharm@gmail.com

${ }^{3}$ Senior Medical Officer, CENAR Hospital, Quetta, Pakistan. Email: shehla.iftikhar@gmail.com

${ }^{4}$ Strathclyde Institute of Pharmacy and Biomedical Sciences, University of Strathclyde, Glasgow, UK. Email: Brian.godman@strath.ac.uk

${ }^{5}$ Department of Laboratory Medicine, Division of Clinical Pharmacology, Karolinska Institutet, Karolinska University Hospital Huddinge, Stockholm, Sweden. Email: Brian.Godman@ki.se

*Correspondence author: Brian Godman, Strathclyde Institute of Pharmacy and Biomedical Sciences, University of Strathclyde, Glasgow G4 0RE, United Kingdom. Email:

Brian.godman@strath.ac.uk. Telephone: 0141548 3825. Fax: 01415522562 and Department of Laboratory Medicine, Division of Clinical Pharmacology, Karolinska Institutet, Karolinska University Hospital Huddinge, SE-141 86, Stockholm, Sweden. Email: Brian.Godman@ki.se. Telephone: 00468585 81068; Fax: 0046858581070

\begin{abstract}
Aims: Type 2 diabetes (T2DM) is a growing burden among all countries including Pakistan, with medication adherence very important. However, little is known about medication adherence in Pakistan and potential predictors among T2DM patients to provide future guidance. This needs to be addressed. Consequently, the present study sought to assess medication adherence among type 2 diabetic patients in Quetta city, Pakistan. Methods: Questionnaire based, descriptive study among 300 Pakistani patients attending public and private hospitals aged 18 years and above, having a confirmed diagnosis of T2DM, without additional co-morbidities were targeted. Descriptive statistics were used to describe demographic and disease characteristics. The association between socio-demographic data and study variables was compared through Man Whitney / Kruskal Wallis test (where applicable). The factors that were significantly associated with medication adherence were further assessed by logistic regression analysis. Results: 55.6\% of patients had high adherence although overall patients reported moderate adherence. Age, gender, education, diabetes-related knowledge and treatment satisfaction were significantly associated with medication adherence. Older males with only primary education and with poor diabetes-related knowledge had the lowest adherence. Conclusions: This study presents a model that is associated with medication adherence among T2DM patients, with disease-related knowledge as a significant predictor of likely adherence. Results of the current study revealed that improved diabetes related knowledge plays a significant role in improving medication adherence. Healthcare practitioners and the system should formalize and acknowledge patient education as a key component to treat patients with T2DM. This should include a greater role for pharmacists and other professionals.
\end{abstract}

Key words: Prescribing, medicine use, Diabetes, Pakistan 
(Accepted for publication Postgraduate Medicine - Please keep CONFIDENTIAL)

\section{Introduction}

Diabetes mellitus (DM) is a metabolic disorder characterized by hyperglycemia due to defects in insulin secretion, insulin action or both. Type 2 Diabetes Mellitus (T2DM) accounts for approximately $90 \%$ of all DM patients. ${ }^{[1]}$ Persistent hyperglycemia results in micro and macrovascular complications, which together with their prevalence, results in DM being the seventh leading cause of death worldwide. ${ }^{[2]}$ According to the International Diabetes Federation, currently 415 million people world-wide suffer from diabetes. This figure is expected to increase to 642 million by $2040^{[3]}$, driven principally by a $69 \%$ increase in diabetes prevalence in developing countries. ${ }^{[4]}$ Furthermore, mortality rates as high as $80 \%$ of the population due to noncommunicable disease (NCDs) have been reported among developing countries. ${ }^{[5]}$

Unfortunately, the prevention and management of T2DM in low-resource settings are currently compromised by the socioeconomic situation ${ }^{[5]}$. This is a concern as the disease is manageable including pharmacotherapy with oral hypoglycemic agents, insulin or both. ${ }^{[6]}$ Adherence to medicines is critical to help managing patients with T2DM, with the World Health Organization (WHO) defining adherence as the degree of patients' medication taking behaviour, executing lifestyle changes, and following a diet plan, corresponding with agreed recommendations from the health care provider. ${ }^{[7]}$ In view $f$ concerns with generally poor adherence to medicines, improving poor adherence rates in patients with T2DM with existing medicines is currently seen as more beneficial to health care systems compared with developing new medical treatments. ${ }^{[8]}$

Non-adherence of medicines in patients with T2DM arises from complex treatment regimens including multiple medications and self-care activities such as diet, exercise, foot care and regular glucose monitoring. Consequently, indicators of medication adherence are a valuable source for physicians and other professions to identify patients who are not responding to current regimens and need to improve their adherence rates. ${ }^{[9]}$ Psychological problems, particularly depression, sideeffects of medication, presence of barriers to care, missed appointments and high patient copayments have all been reported as predictors of non-adherence. ${ }^{[10-14]}$

Pakistan is currently ranked seventh in the world regarding the burden of T2DM, ${ }^{[15]}$ with a current incidence varying from 7.6 to $11 \%$ of the population and growing. ${ }^{[16-18]}$ However to date, medication adherence has not been seen as a major concern among health care providers in Pakistan. ${ }^{[19]}$ This may be because little information is currently available regarding adherence rates among these patients, although what information is available suggests poor medication adherence in practice. ${ }^{[20-22]}$ We would like to add to this knowledge by looking specifically at potential key predictors of medication adherence as a starting point for developing future initiatives in Pakistan. Consequently, the objectives of this paper are to review current adherence to medicines among T2DM patients in Pakistan and possible predictors of poor adherence. Subsequently use the findings to suggest potential future initiatives that could be introduced to improve adherence rates should this be a concern given the growing prevalence of T2DM in Pakistan and the subsequent impact on morbidity, mortality and costs if not adequately addressed. 


\section{Subjects, Materials and Methods}

\section{Study design, inclusion criteria and settings}

The study was designed as a questionnaire-based descriptive analysis. Pakistani nationals aged 18 years and above, having a confirmed diagnosis of T2DM, without additional co-morbidities, were targeted for the study. A diagnosis of diabetes including HbA1c levels and other disease related information was taken from medical records. Having a familiarity of Urdu (the official language of Pakistan) was also important for taking part in the study. The study was initiated in October 2015 and lasted until March 2016. T2DM patients from both public (Sandamen Provisional Hospital and Bolan Medical Complex Hospital) and private hospitals (Alkahir Hospital, Alshafi Hospital and Sajid Hospital) located in Quetta city were approached by the principal investigator (QI) for data collection at the outpatient departments of the respective hospitals. This city was chosen as being representative of Pakistan. Both public and private hospitals were included to make sure a representative sample of patients were included, with T2DM patients typically treated in out-patient clinics. Currently in Pakistan, patients attending private facilities pay $100 \%$ out of pocket. There is currently mixed payments in public facilities. The consultation is free in public institutes. However, only a limited number of medicines are available free to patients and they have to buy the rest out of pocket.

\section{Sampling criteria}

A prevalence based sampling method was used to calculate the minimum sample required for this study, ${ }^{[23]}$ with a prevalence of $11 \%$ taken from reported studies. ${ }^{[24]}$ However to minimize potential bias in sampling, a cumulative double design was added to the sampling initial frame and respondents were approached until we reached 300 for this study. ${ }^{[24]}$

\section{Study variables and data collection}

The study drew its frame work from the extensive literature on this subject ${ }^{[25-29]}$. The first author administered all the questionnaires and was solely involved in the data collection process. In addition to the demographics, diabetes-related knowledge and treatment satisfaction were taken as independent variables affecting medication adherence in the regression model. For prescribed medications, the medications that were prescribed for T2DM were taken into consideration. The above mentioned variables were assessed via validated questionnaires and permission was taken from the developers prior to data collection.

\section{Assessment of medication adherence}

The validated Drug Attitude Inventory (DAI-10) questionnaire in Urdu (National language of Pakistan) was used for the assessment of medication adherence. ${ }^{[25]}$ DAI-10 is a generalized adherence measure consisting of ten questions that assess treatment adherence to all therapeutic regimens. Responses consist of yes or no, and scores range from 10 to -10 . Patients with scores 610 were reported as adherent, $0-5$ as moderate adherent and those in the negative ranges as nonadherent ${ }^{[25]}$. DAI-10 is frequently used for assessment of medication adherence and is previously being used in the healthcare setting of Pakistan. ${ }^{[30]}$

\section{Assessment of diabetes-related knowledge}

The validated Urdu version of Michigan Diabetes Knowledge Test (MDKT) was used for the assessment of diabetes-related knowledge. ${ }^{[31]}$ The MDKT was scored as zero for incorrect response 
and one for a correct response consequently, knowledge scores ranged from $0-14$. The range of knowledge score was categorized in three different ways (poor knowledge $<7$, average knowledge 7-11 and good knowledge $>11)^{[32]}$.

\section{Assessment of treatment satisfaction}

Treatment satisfaction was based on the subjective assessment of T2DM patients' experiences towards healthcare professionals and the available facilities. The patients were given options to state the level of satisfaction as 'satisfied, being neutral or dissatisfied'.

\section{Other patient variables}

Other variables such as patients' education, occupation, income, locality, duration of the disease and family history of diabetes were asked in the questionnaire to add to the information contained in the patients' notes.

\section{Ethical approval}

Institutional Review Board, Faculty of Pharmacy, University of Sargodha, Pakistan approved the study (22-2015/PREC/FOP/UOS). Additionally, permission to conduct the study was taken from the medical superintendent of the respective institutes. Written consent was also taken from the patients prior to data collection. The patients were informed about the research initiatives, confidentiality of their responses and their right to withdraw from the study with no penalty or effects on their treatment.

\section{Statistical analysis}

The KS test was used for normality analysis and non-parametric test were used accordingly.

Descriptive statistics were used to describe demographic and disease characteristics of the patients. Percentages and frequencies were used for the categorical variables, while means and standard deviations were calculated for the continuous variables. The characteristics of the whole sample, medication adherence scores and diabetes-related knowledge scores were presented.

Medication adherence and diabetes-related knowledge were calculated using the criteria originated by the developers. The association between socio-demographic data and study variables was compared through Man Whitney / Kruskal Wallis test (where applicable). The factors that were significantly associated with medication adherence were further assessed by logistic regression analysis. The logistic regression analysis included parameters with $\mathrm{p}$ value $<0.05$ in the Man Whitney / Kruskal Wallis test. The power of independently related parameters and predictive models were expressed as odds ratio (OR) with 95\% confidence intervals (CI). SPSS v. 20.0 was used for data analysis and results for all analyses were considered statistically significant at $\mathrm{p}<0.05$.

We did not break the patients down in those attending private or public facilities as the main difference was whether the consultation fee was free or not. However, we did break the patients down into key factors including occupation and income levels. 


\section{Results}

The study was conducted from October, 2015 to March, 2016. A total of 1520 patients were treated during the recruitment period. However, only 330 subsequently fulfilled the inclusion criteria. Three hundred T2DM patients were finally incorporated in the study as the remaining patients subsequently declined to participate in the study. The description of socio-demographic variables and frequency distribution of the respondents are summarized in Table 1. 
Table 1: Characteristics of the study respondents $(n=300)$

\begin{tabular}{|c|c|c|}
\hline Characteristics & Frequency (n) & Percentage (\%) \\
\hline \multicolumn{3}{|l|}{ Age group (51.25 \pm 9.59$)$} \\
\hline $30-40$ & 43 & 14.3 \\
\hline $41-50$ & 120 & 40.0 \\
\hline $51-60$ & 90 & 30.0 \\
\hline$>60$ & 47 & 15.7 \\
\hline \multicolumn{3}{|l|}{ Gender } \\
\hline Male & 180 & 60.0 \\
\hline Female & 120 & 40.0 \\
\hline \multicolumn{3}{|l|}{ Education } \\
\hline Primary & 92 & 30.7 \\
\hline Middle & 41 & 13.7 \\
\hline Metric & 69 & 23.0 \\
\hline Intermediate & 34 & 11.3 \\
\hline Graduate & 21 & 7.0 \\
\hline Postgraduate & 43 & 14.3 \\
\hline \multicolumn{3}{|l|}{ Occupation } \\
\hline Unemployed & 127 & 42.3 \\
\hline Government Employee & 84 & 28.0 \\
\hline Private Employee & 35 & 11.7 \\
\hline Businessman & 54 & 18.0 \\
\hline \multicolumn{3}{|c|}{ Income *(Pakistan Rupee $)$} \\
\hline No Income & 96 & 32.0 \\
\hline$<5000$ & 64 & 21.3 \\
\hline $5000-10000$ & 46 & 15.3 \\
\hline $10001-15000$ & 13 & 4.3 \\
\hline$>15000$ & 81 & 27.0 \\
\hline \multicolumn{3}{|l|}{ Locality } \\
\hline Urban & 112 & 37.3 \\
\hline Rural & 188 & 62.7 \\
\hline \multicolumn{3}{|c|}{ Duration of disease (years) } \\
\hline Less than 1 year & 54 & 18.0 \\
\hline $1-3$ years & 97 & 32.3 \\
\hline $3-5$ years & 58 & 19.3 \\
\hline More than 5 years & 91 & 30.3 \\
\hline \multicolumn{3}{|l|}{ Family history of diabetes } \\
\hline Yes & 166 & 55.3 \\
\hline No & 134 & 44.7 \\
\hline \multicolumn{3}{|c|}{ Number of prescribed drugs } \\
\hline $1-3$ & 279 & 93.0 \\
\hline More than 3 & 21 & 7.0 \\
\hline \multicolumn{3}{|c|}{ Overall, are you are satisfied with present treatment? } \\
\hline Satisfied & 182 & 60.7 \\
\hline Neutral & 33 & 11.0 \\
\hline Dissatisfied & 85 & 28.3 \\
\hline
\end{tabular}


The mean age (SD) of the patients was 51.25 (9.59) years, with males (60\%) dominating the cohort. Ninety-two (30.7\%) patients had primary level of education with $42.3 \%$ currently unemployed. $55.3 \%$ had a family history of T2DM, with $62.7 \%$ residing in rural locations. Overall, 60.7\%were satisfied with their present treatment and consultation (Table 1).

Table 2 presents the level of diabetes-related knowledge in the current study respondents. Out of the 300 respondents, 210 (70.0\%) were within the poor knowledge range, $83(27.6 \%)$ moderate and only seven patients $(2.3 \%)$ showed adequate general knowledge about T2DM. Poor knowledge using the MDKT-14 knowledge score was apparent in responses to questions relating to diet and disease related information. The mean knowledge score was $5.83 \pm 1.92$, indicating generally poor diabetes-related knowledge among T2DM patients.

\section{Table 2: Description of diabetes-related knowledge among the study participants}

\begin{tabular}{|c|c|c|c|c|}
\hline Diabetes Knowledge items & $\begin{array}{c}\text { Frequency } \\
\text { (n) }\end{array}$ & $\begin{array}{c}\text { Percent } \\
(\%)\end{array}$ & $\begin{array}{l}\text { True } \\
\text { (n) }\end{array}$ & $\begin{array}{c}\text { False } \\
\text { (n) }\end{array}$ \\
\hline \multicolumn{5}{|l|}{ The suitable diet for a diabetic is: } \\
\hline The way most Pakistani people eat & 171 & 57.0 & \multirow{4}{*}{72} & \multirow{4}{*}{228} \\
\hline A healthy diet for most people & 77 & 25.7 & & \\
\hline Too high in carbohydrate for most people & 28 & 9.3 & & \\
\hline Too high in protein for most people & 24 & 8.0 & & \\
\hline \multicolumn{5}{|l|}{ Which of the following is highest in carbohydrates? } \\
\hline Baked chicken & 130 & 43.3 & \multirow{4}{*}{54} & \multirow{4}{*}{246} \\
\hline Cheese & 96 & 32.0 & & \\
\hline Baked potato & 57 & 19.0 & & \\
\hline Peanut butter & 17 & 5.7 & & \\
\hline \multicolumn{5}{|l|}{ Which of the following is highest in fat? } \\
\hline Low fat milk & 146 & 48.7 & \multirow{4}{*}{134} & \multirow{4}{*}{166} \\
\hline Orange juice & 117 & 39.0 & & \\
\hline Corn & 20 & 6.7 & & \\
\hline Honey & 17 & 5.7 & & \\
\hline \multicolumn{5}{|l|}{ Which of the following is free food? } \\
\hline Any unsweetened food & 59 & 19.7 & \multirow{4}{*}{27} & \multirow{4}{*}{273} \\
\hline Any dietetic food & 187 & 62.3 & & \\
\hline Any food that says sugar free on the label & 26 & 8.7 & & \\
\hline Any food that has less than 20 calories per serving & 28 & 9.3 & & \\
\hline $\begin{array}{l}\text { Glycosylated haemoglobin (Haemoglobin A1) is a test that is a measure of your average blood glucose level } \\
\text { for the past: }\end{array}$ & & & 131 & 169 \\
\hline Day & 22 & 7.3 & & \\
\hline
\end{tabular}




\begin{tabular}{|c|c|c|c|c|}
\hline Week & 63 & 21.0 & & \\
\hline $6-10$ weeks & 118 & 39.3 & & \\
\hline 6 months & 97 & 32.3 & & \\
\hline \multicolumn{5}{|l|}{ Which is the best method for testing blood glucose? } \\
\hline Urine test & 37 & 12.3 & \multirow{3}{*}{144} & \multirow{3}{*}{156} \\
\hline Blood test & 152 & 50.7 & & \\
\hline Both are equally good & 111 & 37.0 & & \\
\hline \multicolumn{5}{|l|}{ What effect does unsweetened fruit juice have on blood glucose? } \\
\hline Lowers it & 69 & 23.0 & \multirow[t]{3}{*}{121} & \multirow[t]{3}{*}{179} \\
\hline Raises it & 133 & 44.3 & & \\
\hline Have no effect & 98 & 32.7 & & \\
\hline \multicolumn{5}{|l|}{ Which should not be used to treat low blood glucose? } \\
\hline 3 hard candies & 144 & 48.0 & \multirow{4}{*}{87} & \multirow{4}{*}{213} \\
\hline $1 / 2$ cup orange juice & 42 & 14.0 & & \\
\hline 1 cup diet soft drink & 87 & 29.0 & & \\
\hline 1 cup skim milk & 27 & 9.0 & & \\
\hline \multicolumn{5}{|c|}{ For a person in good control, what effect does exercise have on blood glucose? } \\
\hline Raises it & 220 & 73.3 & \multirow{3}{*}{219} & \multirow[t]{3}{*}{81} \\
\hline Lowers it & 54 & 18.0 & & \\
\hline Has no effect & 26 & 8.7 & & \\
\hline \multicolumn{5}{|l|}{ Infection is likely to cause: } \\
\hline An increase in blood glucose & 114 & 38.0 & \multirow{3}{*}{83} & \multirow{3}{*}{217} \\
\hline A decrease in blood glucose & 85 & 28.3 & & \\
\hline Has no change on blood glucose & 101 & 33.7 & & \\
\hline \multicolumn{5}{|l|}{ The best way to take care of your feet is to: } \\
\hline Look at and wash them each day & 133 & 44.3 & \multirow{4}{*}{145} & \multirow{4}{*}{155} \\
\hline Massage them with alcohol each day & 66 & 22.0 & & \\
\hline Soak them for one hour each day & 77 & 25.7 & & \\
\hline Buy shoes a size larger than usual & 24 & 8.0 & & \\
\hline \multicolumn{5}{|l|}{ Eating food lower in fat decrease your risk for: } \\
\hline Nerve disease & 115 & 38.3 & \multirow{4}{*}{113} & \multirow{4}{*}{186} \\
\hline Kidney disease & 60 & 20.0 & & \\
\hline Heart disease & 113 & 37.7 & & \\
\hline Eye disease & 12 & 4.0 & & \\
\hline \multicolumn{5}{|l|}{ Numbness and tingling may be symptoms of: } \\
\hline Kidney disease & 39 & 13.0 & \multirow{4}{*}{181} & \multirow{4}{*}{119} \\
\hline Nerve disease & 178 & 59.3 & & \\
\hline Eye disease & 76 & 25.3 & & \\
\hline Liver disease & 7 & 2.3 & & \\
\hline Which of the following is usually not associated with diabetes? & & & 229 & 71 \\
\hline
\end{tabular}




\begin{tabular}{|c|c|c|}
\hline Vision problem & 23 & 7.7 \\
\hline Kidney problem & 27 & 9.0 \\
\hline Nerve problem & 30 & 10.0 \\
\hline Lung problem & 220 & 73.3 \\
\hline
\end{tabular}

Knowledge was assessed by giving 1 to correct answer and 0 to the wrong answer. The scale measured knowledge from maximum 14 to minimum 0.

Scores $<7$ were taken as poor, $7-11$ average, and $>11$ good knowledge of diabetes. Mean knowledge was $5.83 \pm 1.92$

Table 3 presents the level of adherence in the current study respondents using the DAI-10. Among all the participants, 22 (7.3\%) were low-adherers, $111(37.0 \%)$ were medium adherers and $167(55.6 \%)$ were considered adherent to medication therapies. The mean adherence score was $4.94 \pm 2.72$, indicating moderate level of adherence in this cohort of T2DM patients using the DAI-10 methodology.

Table 3: Description of medication adherence among the study participants

\begin{tabular}{|c|c|c|c|c|}
\hline \multirow[t]{2}{*}{ Drug adherence item } & \multicolumn{2}{|c|}{ False } & \multicolumn{2}{|c|}{ True } \\
\hline & $\mathbf{n}$ & $\%$ & n & $\%$ \\
\hline For me the good things about medication outweigh the bad & 177 & 59.0 & 123 & 41.0 \\
\hline I feel uncomfortable on medication & 221 & 73.7 & 79 & 26.3 \\
\hline I take medications of my own choice & 25 & 8.3 & 275 & 91.7 \\
\hline Medications make me more relaxed & 39 & 13.0 & 261 & 87.0 \\
\hline Medication make me tired and sluggish & 164 & 54.7 & 135 & 45.3 \\
\hline I take medication only when I am sick & 173 & 57.7 & 127 & 42.3 \\
\hline I feel more normal on medication & 17 & 5.7 & 283 & 94.3 \\
\hline It is unnatural for my mind and body to be controlled by medications & 163 & 54.3 & 137 & 45.7 \\
\hline My thoughts are clearer on medication & 23 & 7.7 & 277 & 92.3 \\
\hline By staying on medications, I can prevent getting sick & 20 & 6.7 & 280 & 93.3 \\
\hline
\end{tabular}

Adherence was assessed by giving 1 to correct answer and -1 to the wrong answer. The scale measured adherence from a maximum of 10 to a minimum of -10. Any negative score was rated as poor adherence, 0 - 5 as moderate adherence and $6-10$ as good adherent. Mean adherence was $4.94 \pm 2.72$. 
Table 4 presents the cross tabulation analysis between socio-demographics and study variables. Man Whitney / Kruskal Wallis test reported a significant association between age, gender (males), education, diabetes-related knowledge ( $<<0.05$ ). Older males having primary education and with poor diabetes-related knowledge were identified as an influencing cohort through Bonferroni correction.

No significant association was reported among other variables.

\section{Table 4: Association among socio-demographics and medication adherence}

\begin{tabular}{|c|c|}
\hline \multirow[t]{2}{*}{ Characteristics } & P-Value ${ }^{*}$ \\
\hline & Medication Adherence \\
\hline Age* & 0.006 \\
\hline Gender** & 0.003 \\
\hline Education* & 0.032 \\
\hline Occupation* & 0.077 \\
\hline Income* & 0.450 \\
\hline Locality** & 0.613 \\
\hline Duration of disease (years)* & 0.795 \\
\hline Family history of diabetes** & 0.239 \\
\hline Number of prescribed drugs* & 0.156 \\
\hline Diabetes-related knowledge* & 0.032 \\
\hline Treatment satisfaction $* *$ & 0.066 \\
\hline
\end{tabular}

Logistic regression analysis of the model was performed after entering the considered independent variables to assess potential associations. In the logistic analysis age, gender, education, diabetes-related knowledge and treatment satisfaction were included as study parameters. The created model showed a significant goodness of fit as the Omnibus Test of Model Coefficient was highly significant $(\mathrm{Chi}$ square $=11.342, \mathrm{p}=0.001, \mathrm{df}=4)$. The knowledge score had a significant association $($ adjusted $\mathrm{OR}=2.232,95 \% \mathrm{CI}=$ $1.345-1.766, \mathrm{P}<0.001)$ with medication adherence. An increase in knowledge score of one point is associated with increase in good adherence by a factor of 2.232 provided other confounding factors are controlled. 


\section{Discussion}

The current study aimed to highlight the predictors of medication adherence in a T2DM population attending both public and private facilities in Pakistan. As the patients were targeted randomly, chances of bias were minimized to give additional strength to the study design and findings. There appeared to be moderate adherence (Table 3), with diabetes-related knowledge appearing as a positive predictor of medication adherence (Table 4). This is encouraging as previous studies conducted in other parts of Pakistan reported poor medication adherence among diabetes patients. ${ }^{[19-21]}$ Poor medication adherence has also been observed among diabetes patients in the South Asian region. ${ }^{[26-28]}$ One possible reason for the differences seen between the various studies is the different methodologies used to assess medication adherence. The literature reports a number of direct and indirect adherence measures, but there currently appears no gold standard method. ${ }^{[29}$ Although different methods are advocated, a combination of measures could improve the accuracy in recording current medication adherence rates. Consequently, we believe it is wise in the future to use multiple medication adherence tools in order to obtain a better picture of current adherence rates among diabetic patients, which we attempted to undertake in this study.

Diabetes-related knowledge was reported as a predicting factor of medication adherence in the current study (Table 4). Our findings are in line with others whereby diabetes-related knowledge was found to be a correlating factor influencing medication adherence, ${ }^{[27,} 33$,

${ }^{34]}$ which is perhaps not surprising. However, developing countries are faced with limited resources, poor infrastructures and ill equipped healthcare system. Communicable diseases are generally more prevalent and less attention has typically been paid to the management of NCDs like T2DM in these countries. Additionally, when compared with communicable diseases, currently few policies have been designed and implemented at administrative levels to better manage NCDs such as T2DM. ${ }^{[35]}$ However, this is changing, ${ }^{[5]}$ with the WHO and others highlighting the importance of improved prevention and management of these patients including improving adherence rates with current medicines. ${ }^{[36]}$ Against this, in Pakistan, patients typically pay most of their healthcare costs out-of-pocket, and the choice of consulting a registered health care professional is generally the last option. Patients generally prefer to consult other sources, including traditional healers and alternative therapists, first before seeking professional care. The poor knowledge gained can shape future medication taking behaviour and management including patients with T2DM. Consequently, in order to change the medication taking behaviour of T2DM patients, dissemination of the right information at the communal level is needed so that patients can understand the benefits of consulting registered healthcare professionals and the potential harms related to illegal and unauthorized health care practices. The findings in this study further highlight the challenges involved given variable knowledge and variable medication adherence levels even among patients attending outpatient clinics in hospitals (Table 2 and 3 ). This can involve all key stakeholder groups, including potentially religious leaders and others ${ }^{[37]}$.

Ideally all oral medicines to treat patients with T2DM should be available free, including oral anti-diabetic medicines, medicines to control BP as well as statins given concerns with issues of co-payments, with commercial organisations believing they can supply such 
medicines for US\$1/ patient/ month/ medicine. ${ }^{[38,39]}$ This is a consideration for the future in Pakistan given its manufacturing base alongside suggestions to improve the quality of locally produced generics. ${ }^{[40}$

Another issue for the authorities in Pakistan to consider is collaborative care, which is typically not practiced at healthcare institutions. Physicians currently have limited interaction with pharmacists while designing therapeutic regimens for their patients ${ }^{[41]}$, and pharmacists face certain barriers with providing clinical services. Currently, hospital and other pharmacists in Pakistan do not typically provide education to patients. ${ }^{[42]}$ As a result, diabetes patients in Pakistan may not always receive the required information to improve their medication adherence (Table 4). Consequently, a collaborative care approach is recommended with pharmacists and other healthcare professionals, including physicians and nurses working together and providing information to patients on the medicines they should take and the need to adhere to them. As a result, patients will become more empowered. This could include potentially Diabetes Nurse Educators in the future, with such initiatives already happening in some countries ${ }^{[43-48]}$. This needs to be taken forward in Pakistan. Once patients are empowered with the right diabetes-related knowledge, medication taking behaviour can be improved (Table 4) and the objectives of treatment attained. We will be following this up with further research and initiatives to improve the care of patients with T2DM in Pakistan.

Alongside this, we will also be looking at ways to generally improve physician knowledge of medicines and their place in care since previous research has shown most physicians in Pakistan still rely on pharmaceutical companies for their source of information. [,49] Pharmacists and other professionals can play a role in developing services such as independent advice through Drugs and Therapeutic Committees to enhance future medicine selection and use. ${ }^{[50-]}$ Future activities will also include researching potential ways to reduce patient reliance on traditional healers and alternative therapists, since without this care will continue to be sub-optimal.

We are aware that our study included hospitals from only one city in Pakistan. However, we believe that our findings are robust in view of the number of patients involved and provide direction for the future. We will though be following this up with further research in other cities given the concerns that we identified.

\section{Conclusion}

Medication adherence among diabetes patients is a concern across countries including Pakistan. A distinctive feature of this study is that it focused T2DM patients without co morbidities that to the best of our knowledge is the first of its kind from Pakistan. Results of the current study revealed that improved diabetes related knowledge plays a significant role in improving medication adherence. Thus, it is suggested that improved knowledge of T2DM and its management can reshape medication taking behaviour, which in return will improve glycemic control and reduce the complications associated with T2DM. Healthcare systems should formalize and acknowledge patient education as a key component of therapeutic plans in order to improve future adherence rates. As a result, help reduce the 
complications associated with T2DM and the subsequent impact on morbidity, mortality and costs. Pharmacists along with physicians and other professionals can play an increasing role to improve patient care in Pakistan through co-ordinated approaches, building on the success in other countries. This should become a goal in Pakistan along with initiatives to reduce patient co-payments. Without such initiatives, care of these patients will continue to be sub-optimal.

\section{Limitations}

The study was conducted based on a prevalence based approach. We believe that the sample is representative of the region but we acknowledge that a larger scale study across different regions in Pakistan is recommended to generalize the findings.

\section{Acknowledgement}

We acknowledge the patients and practicing staff for the help in completion of this study.

\section{Conflicts of interest and funding}

The authors have no conflict of interest to declare. No funding was received for this study.

\section{References}

1. ADA. Diagnosis and classification of diabetes mellitus. Diabetes care, 2010; 33(Supplement 1): S62-S69

2. ADA. Standards of medical care in diabetes - 2014. Diabetes Care, 2014; 37: S14 - S80

3. IDF diabetes atlas: global estimates of the prevalence of diabetes for 2015 and 2040. Available at URL: http://www.diabetesatlas.org/

4. Shaw JE, Sicree RA, Zimmet PZ. Global estimates of the prevalence of diabetes for 2010 and 2030. Diabetes research and clinical practice, 2010; 87(1): 4-14

5. Riaz H, Godman B, Bashir S et al. Evaluation of drug use indicators for non-communicable diseases in Pakistan. ActaPoloniaePharmaceutica, 2016; 73(3): 787-794

6. ADA. Standards of Medical Care in Diabetes - 2013. Diabetes Care. 2013; 36(Supplement 1): S11-S66

7. WHO. Adherence to long term therapies. Available at URL:

http://www.who.int/chp/knowledge/publications/adherence_Section1.pdf

8. Sabaté E. Adherence to long-term therapies: evidence for action: World Health Organization. 2003. Available at URL:

http://apps.who.int/iris/bitstream/10665/42682/1/9241545992.pdf

9. DiMatteo M R, Sherbourne CD, Hays RD et al Physicians' characteristics influence patients' adherence to medical treatment: results from the Medical Outcomes Study. Health Psychology, 1993; 12(2): 93-102

10. Van Servellen G, Chang B, Garcia L et al. Individual and system level factors associated with treatment non adherence in human immunodeficiency virus-infected men and women. AIDS Patient Care and STDs, 2002; 16(6): 269-281 
11. Barbui C, Conti V. Adherence to generic v. brand antidepressant treatment and the key role of health system factors. Epidemiology and Psychiatric Sciences, 2015; 24(01): 23-26.

12. Roberts B, Stickley A, Balabanova D, McKee M. Irregular treatment of hypertension in the former Soviet Union. Journal of Epidemiology and Community Health, 2012; 66(6): 482-488.

13. Shrank WH, Hoang T, Ettner SL et al. The implications of choice: prescribing generic or preferred pharmaceuticals improves medication adherence for chronic conditions. Archives of Internal Medicine, 2006; 166(3): 332-337

14. Simoens S, Sinnaeve PR Patient co-payment and adherence to statins: a review and case studies. Cardiovascular Drugs and Therapy, 2014; 28(1): 99-109.

15. Khan MA, Sultan SM, Nazli R et al. Depression among patients with type-2 diabetes mellitus. Journal of the College of Physicians and Surgeons Pakistan, 2014; 24(10): 770-771

16. IDF. Prevalence estimates of Diabetes Mellitus (DM) - MENA 2010. Available from URL: from http://www.idf.org/content/mena-data

17. Jafar T, Levey A, White Fet al. Ethnic differences and determinants of diabetes and central obesity among South Asians of Pakistan. Diabetic Medicine, 2004; 21(7): 716-723

18. Shera A, Jawad F, Maqsood A. Prevalence of diabetes in Pakistan. Diabetes Research and Clinical Practice, 2007; 76(2): 219-222 19. Abbas A, Kachela B, Arif JM et al. Assessment of medication adherence and knowledge regarding the disease among ambulatory patients with diabetes mellitus in Karachi, Pakistan. Journal of Young Pharmacists, 2015; 7(4): 329-340

20. Imtiaz S, Ullah H, Rasool MF et al. Assessment of compliance of diabetic patients at nishtar hospital Multan, Pakistan. Gomal Journal of Medical Sciences, 2014; 12(2): 84-88

21. Nazir SUR, Hassali MA, Saleem F et al. Disease related knowledge, medication adherence and glycaemic control among patients with type 2 diabetes mellitus in Pakistan. Primary Care Diabetes, 2016; 10(2): 136-141

22. Shams N, Amjad S, Ahmed W, Saleem F. Drug non-adherence in type 2 diabetes mellitus; predictors and associations. Journal of Ayub Medical College Abbottabad, 2016; 28(2): 302-307

23. Daniel WW. Biostatistics: basic concepts and methodology for the health sciences. 2010. New York: John Wiley \& Sons.

Available at URL: https://www.amazon.co.uk/Biostatistics-Concepts-Methodology-Probability-Statistics/dp/0470413336

24. Gorstein J, Sullivan KM, Parvanta I et al. Indicators and methods for cross-sectional surveys of vitamin and mineral status of populations. Available from URL: http://www.who.int/vmnis/toolkit/mcn-micronutrient-surveys.pdf

25. Saleem F, Hassali M, Shafie AA et al. Association between knowledge and drug adherence in patients with hypertension in Quetta, Pakistan. Tropical Journal of Pharmaceutical Research, 2011; 10(2): 125-132.

26. Chong E, Wang H, King- Shier K et al. Prescribing patterns and adherence to medication among South- Asian, Chinese and white people with Type 2 Diabetes Mellitus: a population- based cohort study. Diabetic Medicine, 2014; 31(12): 1586-1593

27. Divya S, Nadig P. Factors contributing to non-adherence to medication among type 2 diabetes mellitus in patients attending tertiary care hospital in South India. Asian Journal of Pharmaceutical and Clinical Research, 2015; 8(2): 274-276 
28. Pirdehghan A, Poortalebi N. Predictors of Adherence to Type2 Diabetes Medication. Journal of Research in Health Sciences, 2016; 1(16): 72-75

29. Osterberg L, Blaschke T. Adherence to medication. NEJM 2005; 353(5): 487-497

57. Saleem F, Hassali MA, Shafie AA etal. Does treatment adherence coorelates with health related quality of life? Finings from a cross sectional study. BMC Public Health. 2012;12:318

31. Saleem F, Hassali M, Shafie A et al. Translation and Validation Study of 14-Item Michigan Diabetes Knowledge Test (MDKT): The Urdu Version. Value in Health, 2011; 14(7): A481

32. Al-Qazaz HK, Hassali MA, Shafie AA, Sulaiman SAS, Sundram S. The 14-item Michigan Diabetes Knowledge Test: translation and validation study of the Malaysian version. Pract Diab Int 27(6):238-41a.

33. Abebaw M, Messele A, Hailu M et al. Adherence and Associated Factors towards Antidiabetic Medication among Type 2 Diabetic Patients on Follow-Up at University of Gondar Hospital, Northwest Ethiopia. Advances in Nursing, 2016, 1-7

34. Sweileh WM, Sa'ed HZ, Nab'a RJA et al. Influence of patients' disease knowledge and beliefs about medicines on medication adherence: findings from a cross-sectional survey among patients with type 2 diabetes mellitus in Palestine. BMC Public Health, 2014; 14(14): 94

35. Peters DH, Rao KS, Fryatt R. Lumping and splitting: the health policy agenda in India. Health Policy and Planning, 2003; 18(3), 249-260

36. WHO Organization, 2016. Available at URL: http://apps.who.int/iris/bitstream/10665/204871/1/9789241565257 eng.pdf?ua=1

37. Riaz H, Finlayson AE, Bashir Set al. Prevalence of Vitamin D deficiency in Pakistan and implications for the future. Expert review of clinical pharmacology. 2016;9(2):329-38

38. Editorial. Kenya first country to launch 'Novartis Access', expanding affordable treatment options against chronic diseases. Available from URL: https://www.novartis.com/news/media-releases/kenya-first-country-launch-novartis-access-expandingaffordable-treatment

39. Novartis access. Available from URL: https://www.novartis.com/about-us/corporate-responsibility/expanding-accesshealthcare/novartis-access

40. Khan B, Godman B, Babar A et al. Assessment of active pharmaceutical ingredients in the registration procedures in Pakistan: implications for the future. GABI Journal 2016; 5(4):154-63

41. Azhar S, Hassali M, Ibrahim M. Doctors' perception and expectations of the role of the pharmacist in Punjab, Pakistan. Tropical Journal of Pharmaceutical Research, 2010; 9(3): 205-222

42. Azhar S, Hassali MA, Ibrahim MM. Perceptions of hospital pharmacist's role in Pakistan's healthcare system: a cross-sectional survey. Tropical Journal of Pharmaceutical Research, 2011; 10(1): 11-17

43. Community Pharmacy Scottland. (2016). What is the new medicines intervention support tool (NMIST)? Available at URL: http://www.communitypharmacyscotland.org.uk/nhs-care-services/services/chronic-medication-service/new-medicine-interventionsupport-tool/about-the-new-medicine-intervention-support-tool/ 
44. Godman B, Acurcio FA, Guerra Jnr AA, Alvarez-Madrazo S, Faridah Aryani MY, Bishop I et al. Initiatives among authorities to improve the quality and efficiency of prescribing and the implications. Journal of Pharmaceutical Care \& Health Systems, 2014; 8(1): $7-24$

45. Kooij MJ, Heerdink ER, Van Dijk L et al. Effects of telephone counselling intervention by pharmacists (TelCIP) on medication adherence; results of a cluster randomized trial. Frontiers in Pharmacology, 2016; 7: 269

46. The Scottish Government. Prescription for excellence: A vision and action plan for the right pharmaceutical care through integrated partnerships and innovation. 2013. Available at URL: http://www.gov.scot/Publications/2013/09/3025

47. Meece J. Improving medication adherence among patients with type 2 diabetes. J Pharm Pract. 2014;27(2):187-94

48. Antoine S-L, Pieper D, Mathes T et al. Improving the adherence of type 2 diabetes mellitus patients with pharmacy care: a systematic review of randomized controlled trials. BMC Endocrine Disorders, 2014;14(1):53

49. Riaz H, Godman B, Hussain S et al. Prescribing of bisphosphonates and antibiotics in Pakistan: challenges and opportunities for the future. Journal of Pharmaceutical Health Services Research. 2015;6:111-21

50. Holloway K, Green T. Drug and Therapeutics Committees: A practical guide. 2003. Available at URL:

http://apps.who.int/medicinedocs/pdf/s4882e/s4882e.pdf 